\title{
Motives for Mergers and Acquisitions in the Nepalese Perspective
}

\author{
Hari Prasad Pathak ${ }^{*}$
}

\begin{abstract}
This paper attempts to identify the motives of mergers and acquisitions in the Nepalese financial sector.Questionnaire survey method is used to obtain the views of randomly selected 122 bankers of 21 post-merged financial institutions. A two-stage multivariate procedure is used to identify the important factors that drive the merger of financial institutions.In the first stage, an exploratory factor analysis is performed using ten statements that were put in the Likert scale in the questionnaire. In the second stage, important motives of mergers are determined by conducting an ordinary least squares regression using the factors extracted from factor analysis. It checks the internal consistency and reliability of the data using the Cronbach's Alpha. The paper concludes hat the three most important motives for mergers of Nepalese financial institutions are: (i) meeting the regulatory requirement of paid up capital, (ii) realization of economies of scale and scope, and (iii) generation of efficiencies due to synergistic gains.
\end{abstract}

Key words: Mergers and acquisitions, motives, factor analysis, financial institutions

\section{INTRODUCTION}

The banking industry has experienced an unprecedented level of consolidation on a belief that gains can accrue through cost reduction, increased revenue, improved diversification of risks, enhanced management quality, and scale of economies. Mergers and acquisitions may reduce costs if they enable banks to close redundant branches or consolidate back-office functions. Banks could be more productive if they increase the range of products that they can profitably offer. Mergers and acquisitions may also diversify further bank portfolios and thereby reduce the probability of insolvency. Increased diversification then may reduce banks' total costs by reducing desired capital-asset ratios. Thus, mergers and acquisitions in banking sector have become popular as a major way of corporate restructuring in the majority of the countries in the world (Economy Watch, July 2010; Jayadev\&Sensarma, 2007).

Mergers and acquisitions (M\&A) have been, a priori, associated with the strengthening of a firm's financial position and increasing firm value. Firms involved in a consolidation program should benefit operationally and financially as a result of M\&A activity. Mueller (1969) views mergers and acquisitions as a way to achieve monopoly power or practice some other unfriendly activity. Many firms combine to grow in terms of market share so that they can either charge higher prices to buyers or pay low prices to suppliers. According to Shleiferand Vishny (2003), opportunistic managers carry out mergers in order to build an empire or establish themselves or thinking that they can improve the acquired company performance (Roll, 1986).

The synergy hypothesis has been widely documented in the existing literature in an attempt to explain the motive of mergers and acquisitions (Lensink\&Maslennikova, 2008;Carline, Linn,

\footnotetext{
${ }^{*}$ Mr. Pathak is Associate Professor in Faculty of Management, PN Campus.
} 
\&Yadav, 2009). Synergy occurs when the combination of two or more businesses can create more shareholder value than if they were operated separately, through improvement in operating efficiency.

Several studies specifically analyze bank mergers with respect to geography and activity diversifications. Becher and Campbell (2005) argued that legislation that significantly reduced barriers to interstate banking allows banks to make decisions free of geographic restrictions. Less concentrated businesses try to attain market power by merging entities. Market power refers to the increase in a firm's size, which subsequently leads to an increase in market share, to improve its ability for setting prices above competitive levels. Managers sometimes believe that their own evaluation of a target firm is superior to the market's valuation. This can often lead to overpayment due to ego-driven decision-making. Roll (1986) found that "hubris-infected" acquirers pay higher premiums.

Taking the benefit in taxes is one of the reasons for firms to go for mergers and acquisitions. The role of tax as a motive for mergers and acquisitions has twofold. Firstly, tax benefits, such as loss carried forward and investment tax credits can be used to offset the combined companies' taxable income. Secondly, the taxable nature of the transaction will often play a more important role in determining whether the merger takes place than any tax benefits that accrue to the acquiring company.

Nepalese financial sector has been experiencing significant changes since 1980s when the government adopted financial sector liberalization process (Gajurel\&Pradhan, 2012). Flexible licensing policy and deregulation in the financial sector encouraged foreign joint venture banks, domestic private banks and finance companies to operate into the Nepalese market (Gajurel\&Pradhan, 2012). The trend of establishing bank and financial institutions (BFIs) grew more and more and by the December 2011, the number of commercial banks, development banks and finance companies reached to 31,87 , and 79 respectively (www.nrb.org.np). These mushrooming financial institutions (FIs) were able to generate good profits during the initial periods of their establishment. But with the unrestricted entry of FIs in the market, the competition among them increased severely and many of them started facing problem of maintaining adequate capital base as required by the regulatory authority. In order to cope up with such situation, some of them have merged and some are in the merging process. With the enactment of Merger by-law 2012 and Acquisition by-law 2014, it is expected that the number of mergers and acquisitions in the financial sector in Nepal will be further increased.

The objective of this paper is to examine the motives that drive mergers and acquisitions and to identify the most important motives of mergers and acquisitions in the financial sector in Nepal.

\section{LITERATURE REVIEW}

Even though different companies have diverse reasons for engaging in mergers and acquisitions, the main purpose is to create shareholders' value over and above that of the sum of two companies The fundamental objectives of doing mergers and acquisitions involve enhancement of shareholders wealth, increased competitive advantages (i.e. economies of scale or scope or increased market power), expansion of acquirers' assets, sales and the market share.

Attainment of synergic benefits has frequently been found to be a significant merger motive. For example, Maquieira, Megginson, and Nail (1998) examined 260 mergers in the US between 1963 and 1996 and recorded significant net synergistic gains in non-conglomerate mergers and 
insignificant net gains in conglomerate mergers. Bradley, Desai, and Kim (1988) found that a successful merger increases the combined value of the merged entity by an average of 7.4 percent. Another documented firm-level reason for mergers is efficiency. Rhoades (1998) investigated this motive through nine case studies of bank mergers in the US and found significant cost cutting in all cases. Four out of these nine mergers showed clear efficiency gains relative to peers. Bruner (1988) examined excess cash and debt capacity as a motive for mergers and found evidence to support the theory of Myers and Majluf (1984) that suggested that "slack-rich" bidders pair with "slack-poor" targets to create value.

Reducing cost through cost synergies is the very often-mentioned motive for M\&A. This shows that a firm would always be dedicated to finding opportunities to increase its asset base capacity and decreasing costs per unit produced. The theory behind this motive is economies of scale. Maloney and McCormick (1988) in a study of the US industry found evidence to suggest that merger is partially motivated by cost considerations. Jensen (1986) also found cost synergies as benefits coming from takeovers and therefore a driver for this type of activity.

If excess capacity is a motive for M\&A activity it is expected to find firms working close to capacity to stay away from undertaking acquisitions. Andrade and Stafford (2004), in an across industry US based study supported this hypothesis. These researchers found evidence to state that excess capacity is a strong determinant for consolidation in an industry via mergers. The specific asset acquisition hypothesis is a wide explanatory motivation for merger activity across industries. Therefore, the desired valuable asset will vary and will be dependent on specific industry characteristics. McLaughlin and Mehran (1995) in a study that measures abnormal return on stock prices from merger announcement effects found that the positive effect of stock in regulated target utilities is much smaller compared to cases where utilities operate in countries classified as unregulated environments. They interpreted this as an indication that regulation restrains merger activity. Transferring poorly managed or organizationally weak resources to more successful performing firms has been found to be a strong driver for M\&A activity in the literature. The perspective that sees the market for corporate control as an effective method to discipline manager is thoroughly discussed by Jensen and Ruback (1983). These researchers revealed that this effect on the takeover market allowed resources to be transferred to more efficiently run corporations.

The appraisal of conceptual and empirical facets of mergers and acquisitions reveals that abundance of knowledge has been advanced about subject matter and method of doing research in merger and acquisitions.

\section{DATA AND METHODS}

The information on the Nepalese financial institutions (FIs) that underwent merger was obtained from Nepal Rastra Bank. It is found that 50 Nepalese FIs have been merged till July 2013 and they confined to 21 FIs. This paper uses questionnaire survey methodology to ascertain motives of Nepalese financial institutions mergers. The study conducts a survey of randomly selected 122 bankers (10 CEOs, 35 directors, and 77 executive level staff of FIs) of the 21 post-merged FIs through a questionnaire. The questionnaire contained five-point Likert scale items and personal information of the respondents such as name, age, gender, and academic qualification.

As suggested by Lehmann (1989) a two-stage multivariate procedure has been used to identify the important factors that drive the merger of FIs. In the first stage, first of all, various motives behind 
the corporate mergers were identified reviewing the existing literature. Then, those motives that fit in the context of Nepalese FIs mergers were enlisted. These motives were then be transformed in terms of statements. The question was designed to contain ten statements. An exploratory factor analysis was performed using the ten statements as different variables in the Likert scale questionnaire. Internal consistency and the reliability of the data were checked by using the Cronbach's Alpha. The correlation matrix analysis, anti-image correlation matrix, the measure of sampling adequacy (MSA), Kaiser-Meyer-Olkin and Bartlett's test, the initial and rotted solution for factor analysis and the scree-plot test were also used in the process of extracting the factors. In the second stage, important motives of mergers were determined by conducting an ordinary least squares regression using the factors extracted from factor analysis. The data have been analyzed using the Statistical Package for Social Sciences (SPSS) program.

The area of interest, for this article, is to explore the motives that drive FIs in Nepal for merger process. Mergers are driven by a complex set of motives and no single reason may offer full explanation. One can guess a priori which motives are most important, but hard evidence is needed. For this, the respondents were provided with a Likert scale questions containing ten statements. The respondents were asked to rate the various motives on the Likert scale of 1 to 5 (where, $1=$ strongly disagree, and $5=$ strongly agree). This approach provides information on the relative importance of each motives of merger. First, internal consistency and reliability of the data has been checked by using the Cronbach's Alpha. Next, factorability (i.e., how suitable is the data for factor analysis?) of the data has been checked by usingcorrelation matrix, significant at the 0.05 level, and anti-image matrix for diagonals over 0.5. Similarly, sampling adequacy has been checked by using Bartlett's test of sphericity for p-value $<0.05$, and Kaiser-Meyer-Olkin (KMO) measure of sampling adequacy for over 0.6.

After that, a two stage multivariate procedure has been used to identify the important factors that drive the merger of FIs from the viewpoint of acquirers. In the first stage, an exploratory factor analysis is performed using the ten statements in the questionnaire as different variables. In the second stage, ordinary least squares regression is performed using the factors extracted from factor analysis.

\section{RESULTS AND DISCUSSION}

In order to obtain the significant results for various motives in merging process of banks and FIs in Nepal, the following tests have been applied:

\section{Internal Consistency and Reliability Test Results}

The cut-off range of Cronbach's alpha is 0.7-0.8 (Field, 2005). The present study has an alpha of 0.727. It indicates that the data set is reliable enough and that the variables used in the Likert scale questions could be combined together to produce the broad factors. Thus, it is claimed that the data used in this study is consistent and reliable enough.

\section{Sampling Adequacy Test Results}

Following two tests have been used to meet the minimum standard which should be passed before a factor analysis is carried out:

(i) Kaiser-Meyer-Olkin (KMO) measure of sampling adequacy - This measure varies between 0 and 1 , and values closure to one are better. Minimum acceptable value is 0.6. 
(ii) Bartlett's Test of Sphericity - This test accepts the null hypothesis that the correlation matrix is an identity matrix. An identity matrix is a matrix in which all of the diagonal elements are 1 and all off-diagonal elements are 0 . However, the null hypothesis needs to be rejected to continue the factor analysis.

The value of Kaiser-Meyer-Olkinmeasure of sampling for this study is found to be 0.681 , which is greater than 0.6. The p-value of Bartlett's Test of Sphericity is .000 ; and hence the null hypothesis is rejected. Thus this study meets the minimum standard to continue the factor analysis.

\section{Factorability Test Results}

Factorability of the data has been checked by using: (i) correlation matrix, significant at 0.05 level, and (ii) anti-image matrix for diagonals over 0.5. Diagonal elements of anti-image correlation matrix are also called variable MSA. Determination and analysis of variable MSA and general MSA for a collection of variables should be a requisite analysis before any factor analysis of the variables is attempted. The use of variable MSA would facilitate for - (i) achieving more generalizable and stable factor analyses, and (ii) dropping out the collections of variables that appear to be nonfactorable. The correlation matrix shows that all the variables are significantly correlated at least with one variable at 1 percent level of significance. Similarly, the minimum value in the principal diagonal of anti-image correlation is $0.538>0.5$. Thus, both tests support for further analysis without dropping any variable.

\section{Factor Analysis}

Finally, an exploratory factor analysis has been carried out on the data set. This is a technique of data reduction whereby the main factors are extracted that explains the correlation among the observed variables. The Principal Component Analysis (PCA) has been used as the factor extraction method for identifying distinct clusters of observed variables. The broad factors so extracted are further subjected to varimax orthogonal rotation with Kaiser Normalization (Tryfos, 1998). The major results are as follows:

Four Eigenvalues are greater than 1, so there are four factors. Table 1presents therotated component matrix along with the communalities in the last column, denoted by $\mathrm{h}^{2}$. Communalities $\left(\mathrm{h}^{2}\right)$ are the proportion of the variance of variables explained by four factors. They vary from 0.526 to 0.854 . As no any value of communalities is less than 0.5 , the researcher concludes that the extracted factors have sufficient explanation.

A rotated component matrix indicates the relationship between broad factors and the observed variables. It provides the broad factors having non-zero and significant factor loadings with a few variables. In the present study, each row in the rotated component matrix presents the factor loadings for each variable (in total 10 variables are used in the study) spread over four broad factors. Table 1 shows no any variable has cross-loading in the rotated solution. By running rotated component matrix in SPSS, four factors have been extracted as mentioned below.

The variable, such asincrease in the market share, which has the highest loading of .837 in the first factor, is taken as a dependent variable constituting a merger decision. This is because when the merger or takeover of FIs is undertaken for any motive, it will ultimately result in an increase in market share (Banga and Gupta, 2012). 
- $\quad$ Factor 1 incorporated other three variables: Meeting the regulatory requirement of paid up capital with 0.818 loading, Realizing economies of scale and scope with 0.803 loading and generation of efficiencies due to synergistic gainswith 0.795 loading. Factor 1 is named as'Financial Motives.'

Table 1: Rotated Component Matrix

\begin{tabular}{lcccr}
\hline & \multicolumn{3}{c}{ Component } & \multirow{2}{*}{$\mathbf{h}^{\mathbf{2}}$} \\
\cline { 2 - 3 } & $\mathbf{1}$ & $\mathbf{3}$ & $\mathbf{4}$ & \\
\hline Increase in the market share & $\mathbf{8 3 7}$ & & .731 \\
Meeting the regulatory requirement of paid up capital & $\mathbf{. 8 1 8}$ & & .849 \\
Realizing economies of scale and scope & .803 & & .804 \\
Generation of efficiencies due to synergistic gains & .795 & & .854 \\
Expansion through M\&A rather than internal growth & & $\mathbf{. 9 2 1}$ & .816 \\
Entering into new markets & .738 & & .649 \\
Board of directors is not willing to tolerate poor & & $\mathbf{. 8 4 6}$ & .698 \\
performance and therefore initiate a merger & & & \\
Obtaining incentives given for merger by the government & & .724 & .687 \\
Enhancement of marketing and management capabilities & & & $\mathbf{. 7 9 6}$ & .757 \\
Benefits of diversification & & & 741 & .526 \\
\hline
\end{tabular}

Extraction Method: Principal Component Analysis.

Rotation Method: Vari-max with Kaiser Normalization.

- Factor 2 includes two variables: Expansion through M\&A rather than internal growth with .921 loading, and Entering into new markets with .738 loading. Factor 2 is named as 'Expansion Motives.'

- Factor 3 includes two variables:Board of directors is not willing to tolerate poor performance and therefore initiate a merger with .846 loading andobtain incentives given for merger by the governmentwith .724 loading. This factor is named as 'Performance Motives.'

- Factor 4 takes in two variables: Enhancement of marketing and management capabilities with .796 loading and benefits of diversification with .741 loading. This factor is named as 'Strategic Motives.'

- Factor 1 extracts 25.275 percent of the total variance. Likewise, Factor 2, Factor 3 and Factor 4 extract 17.679 percent, 16.135 percent and 15.317 percent of the total variance respectively. The communalities $\left(\mathrm{h}^{2}\right)$ ranges from .526 to .854 (Table 1$)$. As no any value of communalities is less than .5 , it is concluded that the extracted factors have sufficient explanation. 


\section{Regression Analysis}

The four factors derived from factor analysis are put to the second stage of the multivariate analysis, i.e., ordinary least square regression. In this stage, the impact of the four independent variables on the increase in market share is examined. Since the factors used in the regression model are derived through the orthogonal transformations, they are free from multicollinearity problems.

Before running the equation model, first of all, four factor scores in the data file of SPSS have been generated by using the command - Save as variables: Regression method - available in the subcommand scores. This facilitated to calculate the within factor summated scales of four factors. After this the within factor summated scales of four factors have been calculated.

Table 2 presents the calculated mean and standard deviation of the within factor summated scales of four factors as well as reliability (Cronbach's Alpha value) of each factor in the first second and third rows respectively.

Table 2: Mean, Standard Deviation and Cronbach's Alpha of four Summated Scales

\begin{tabular}{lcccc}
\hline & $\begin{array}{c}\text { F1 } \\
\text { Financial } \\
\text { motives }\end{array}$ & $\begin{array}{c}\text { F2 } \\
\text { Expansion } \\
\text { motives }\end{array}$ & $\begin{array}{c}\text { F3 } \\
\text { Performance } \\
\text { motives }\end{array}$ & $\begin{array}{c}\text { S4 } \\
\text { motrategic } \\
\text { motives }\end{array}$ \\
\hline $\begin{array}{l}\text { Within factor mean of } \\
\text { summated scale }\end{array}$ & 11.97 & 7.28 & 5.02 & 7.42 \\
$\begin{array}{l}\text { Within factor S.D. of summated } \\
\text { scale }\end{array}$ & 2.22 & 2.31 & 1.67 & 1.79 \\
$\begin{array}{l}\text { Within factor reliability of items } \\
\text { (Cronbach's alpha) }\end{array}$ & .684 & .721 & .676 & .715 \\
\hline
\end{tabular}

Factor 1 (financial motives) has the highest mean 11.97 (with 2.22 standard deviation) while it is Factor 3 (performance motives) which has lowest mean (with standard deviation of 1.67). It means financial motive (Factor 1) is considered the most important motive in compare to other motives. Cronbach's Alpha used to test the reliability of the items within each factor shows that Factors 2 and 4 have the value of alphas more than 0.7 ; and Factors 1 and 3 also have the alphas almost 0.7. Thus the four summated scales are consistent and reliable.

Increase in market share (Y) has been regressed on Sum_F1 to Sum_F4 using the enter method, which includes all independent variables into the model. The model is:

$\mathrm{Y}=\alpha+\beta_{1}$ Sum_F1 $+\beta_{2}$ Sum_F2 $+\beta_{3}$ Sum_F3 $+\beta_{4}$ Sum_F4

Where,

$\mathrm{Y}=$ Increase in market share

Sum_F1 $=$ Within factor summated scale 1

Sum_F2 $=$ Within factor summated scale 2

Sum_F3 $=$ Within factor summated scale 3

Sum_F4 $=$ Within factor summated scale 4 
The table presents regression of 'increase in market share' on four explanatory variables - (i) within factor summated scale 1, (ii) within factor summated scale 2, (iii) within factor summated scale 3, and (iv) within factor summated scale 4 . Within factor summated scale 1 is the combinations of three variables - meeting the regulatory requirement of paid up capital; realize economies of scale and scope, and generation of efficiencies due to synergistic gains; which is named as financial motives. Within factor summated scale 2 is the combination of two variables expansion through M\&A rather than internal growth and entering into new markets; which is named as expansion motives. Similarly, within factor summated scale 3 is the cluster of two variables -BOD could not tolerate poor performance and initiate merger and to avail the incentives given for merger by regulatory body; which is named as performance motives. Likewise, within factor summated scale 4 combines two variables -enhancing of marketing and management capabilities and benefits of diversification; which is named as strategic motives. t-value is given in column 3 and the significant level is given in the last column.

Table 3: Regression Results

\begin{tabular}{lccc}
\hline Variables & $\begin{array}{c}\text { Unstandardized } \\
\text { coefficients beta }\end{array}$ & t-value & Sig. \\
\hline (Constant) & 1.843 & 2.586 & .018 \\
Within factor summated scale 1 & .212 & 6.832 & $\mathbf{. 0 0 0}$ \\
Within factor summated scale 2 & .013 & .321 & .643 \\
Within factor summated scale 3 & -.085 & -1.475 & .118 \\
Within factor summated scale 4 & .066 & 1.207 & .174 \\
\hline $\mathrm{R}^{2}$ & \multicolumn{2}{c}{.474} \\
F-statistic & \multicolumn{2}{c}{14.725} & \\
\hline
\end{tabular}

Table 3 presents the results of the regression model with R-squared value of .474 . The F-Statistic of $14.725(p=0.000)$ is significant at 1 per cent level of significance. Altogether four independent variables were tested in the model. Out of the four variables, three variables - within factor summated scale 1, 2, and 4 - show positive relations with the dependent variable, whereas one variable i.e. within factor summated scale 3 shows a negative relation with the dependent variable. Nevertheless, only one explanatory variable, i.e. within factor summated scale 1 , out of the four explanatory variables, is highly significant at 1 percent level of significance. Since three specific motives of merger are clustered in this summated scale 1, it is concluded that the three most important motives for mergers of Nepalese FIs are: (i) meeting the regulatory requirement of paid up capital, (ii) realization of economies of scale and scope, and (iii) generation of efficiencies due to synergistic gains.

\section{CONCLUSION AND SUGGESTIONS}

In the recent years, the Nepalese banking industry has seen a phenomenal consolidation through a wave of mergers. The wave is continuing. It, therefore, becomes very important to understand the motives of mergers in the Nepalese banking and financial institutions. Though the primary motive of merger and acquisition is to obtain operating synergy, there are many other motives which 
equally drive mergers and acquisitions. With extensive review of related literature, this paper includes various motives of FI mergers that fit in the Nepalese context.The paper uses a two-stage multivariate procedure to identify the important factors that drive the merger of financial institutions from the viewpoint of acquirers.

The study concludes that (i) meeting the regulatory requirement of paid up capital, (ii) realization of economies of scale and scope, and (iii) generation of efficiencies due to synergistic gainsare the three most important motives for mergers. This is the first study of its kind in the Nepalese context. Therefore, the study is important to the shareholders, potential investors, economists, mutual fund companies, and the regulators in order to understand the important motives that drive mergers and acquisitionsof FIs and their implications in investment strategy and formulation of regulations for the financial sector.

Since the wave of mergers and acquisition is on-going in Nepal, further changes in terms of motives are yet to be uncovered. Further investigations using robust research designs are also warranted because many qualitative phenomena of mergers motives like agency problems, managerialism, hubris hypothesis, and market power hypothesis cannot be captured through simple methods. Further research could also be conducted to see the stock market reaction to announcement of FIs mergers and to analyze the post-merger performance of financial institutions.

\section{REFERENCES}

Andrade, G., \& Stafford, E. (2004).Investigating the economic role of mergers.Journal of Corporate Finance,10, 1-36.

Banga, C., \& Gupta, A. (2012).Motives for mergers and takeovers in the Indian mutual fund industry.Vikalpa,37(2), 32-42.

Becher, D. A., \& Campbell, T. L. (2005). Interstate banking deregulation and the changing nature of bank mergers.Journal of Financial Research, 28(1), 1-20.

Bradley, M., Desai, A., \& E.H. Kim.(1988). Synergistic gains from corporate acquisitions and their division between the stockholders of target and acquiring firms.Journal of Financial Economics, 21, 3-40.

Bruner, R. F. (1988). The use of excess cash and debt capacity as a motive for merger.Journal of Financial and Quantitative Analysis, 23(2), 199-219.

Carline, N. F., Linn, S. C., \&Yadav, P. K. (2009). Operating performance changes associated with corporate mergers and the role of corporate governance. Journal of Banking and Finance, 33, 1829-1841.

Economy Watch. (17 July 2010). Merger and acquisition in banking sector. Retrieved from http://www.economywatch.com/mergers-acquisitions/international/banking-sector.html

Field, A. P. (2005). Reliability analysis: Discovering statistics using SPSS (2 ${ }^{\text {nd }}$ ed.). London: Sage Publications.

Gajurel, D. P., \&Pradhan, R. S. (2012). Concentration and competition in Nepalese banking.Journal of Business, Economics and Finance, 1, 5-16.

Jayadev, M., \&Sensarma, R. (2007).Mergers and acquisitions in PSU banks: A research report submitted to the Indian Institute of Banking and Finance (IIBF), Mumbai.

Jensen, M. C. (1986). Agency costs of free cash flow, corporate finance and takeovers. American Economic Review, 76( 2), 323-329. 
Jensen, M. C., \&Ruback, R. S. (1983). The market for corporate control: The scientific evidence. Journal of Financial Economics, 11, 5-50.

Lehmann, D. R. (1989).Marketing research and analysis ( $3^{\text {rd }}$ ed.). Illinois: Irwin, Homewood.

Lensink, R., \&Maslennikova, I. (2008).Value performance of European bank acquisitions.Applied Financial Economics, 18, 185-198.

Maloney, M. T., \& McCormick, R. E. (1988). Excess capacity, cyclical production, and merger motives: Some evidence from the capital markets. Journal of Law and Economics, 31(2), 321-350.

Maquieria, C., Megginson, W., \& Nail, J. (1998).Wealth creation versus wealth redistribution in pure stock-for-stock mergers.Journal of Financial Economics, 48, 3-33.

McLaughlin, R. M., \&Mehran, H. (1995). Regulation and the market for corporate control: Hostile tender offers for electric and gas utilities. Journal of Regulatory Economics, 8, 181-204.

Mueller, D. C. (1969).A theory of conglomerate mergers.Quarterly Journal of Economics, 83, 643-659.

Myers, S. C, \&Majluf, N. S. (1984). Corporate financing and investment decisions when firms have information that investors do not have. Journal of Financial Economics,13, 187221.

Rhoades, S. A. (1998).The efficiency effects of bank mergers: An overview of case studies of nine mergers. Journal of Banking \& Finance, 22, 273-291.

Roll, R. (1986). The hubris hypothesis of corporate takeovers.Journal of Business, 59, 197-216.

Shleifer, A., \&Vishny, R. (2003).Stock market driven acquisitions.Journal of Financial Economics, 70, 295-311.

Tryfos, P. (1998). Methods for business analysis and forecasting: Text and cases. New York: John Wiley and Sons Inc. 